\title{
La identidad sitiada en los espacios del exilio chileno en la República Democrática Alemana: Morir en Berlin y Las dos orillas del Elba ${ }^{1}$
}

\author{
Besieged identity in the spaces of Chilean exile \\ in the German Democratic Republic: \\ Morir en Berlin and Las dos orillas del Elba
}

\author{
CLAUDIA TAPIA VÁSQUEZ \\ ${ }^{a}$ Universidad Católica de la Santísima Concepción. Chile. \\ Correo electrónico: ctapia@ucsc.cl
}

La consistencia del relato autodefinitorio depende de la relación con los espacios pues ellos aseguran pertenencia, seguridad y apego, postulado que constituye el impulso para el estudio de las novelas sobre la diáspora chilena en la RDA, Morir en Berlín de Carlos Cerda, y Las dos orillas del Elba de Juan Forch. Analizados de acuerdo a las reflexiones de Emmanuel Lévinas y los aportes de la Psicología ambiental, los textos revelan la historia de un grupo de chilenos que sin poder entrar a la patria tampoco pudo salir del país de acogida, cercado por muros ideológicos y perimetrales. La experiencia cotidiana de los espacios ajenos, inconfortables y precarios provocó una dolorosa fractura identitaria que significó la diferencia entre ser y no ser, entre libertad y esclavitud, entre vivir y rendirse.

Palabras clave: Literatura del exilio chileno, Identidad de lugar, República Democrática Alemana, Carlos Cerda, Juan Forch.

The consistency of a self-image depends on the relationship with space, since it ensures belonging, security and attachment, a postulate that constitutes the impetus for the study of the novels about the Chilean diaspora in the GDR, Morir en Berlin by Carlos Cerda, and Las dos orillas del Elba by Juan Forch. Analyzed according to the reflections of Emmanuel Lévinas and the contributions of Environmental Psychology, the texts reveal the history of a group of Chileans who, without being able to enter their homeland, could not leave their host country, a territory surrounded by ideological and perimeter walls. The daily experience in foreign, uncomfortable and precarious spaces, caused a painful identity fracture that meant the difference between being and not being, between freedom and slavery, between living and surrendering.

${ }^{1}$ Esta investigación está asociada al proyecto DINREG 16/2017 de la Dirección de Investigación de la Universidad Católica de la Santísima Concepción. 
Key words: Literature of the Chilean exile, Place identity, German Democratic Republic, Carlos Cerda, Juan Forch.

En L'irréversible et la nostalgie, Vladimir Jankélévitch propone que la Odisea debe entenderse como cifra del exilio y que Ulises condensa la trama paradigmática de ese castigo, compuesta por la errancia, la nostalgia y el empeño por el retorno. La idea, retomada por Milan Kundera en L'ignorance, da cuenta que el destierro constituye una coordenada fundacional de nuestra civilización, uno de esos "grandes gestos y movimientos simbólicos ejemplares" (Steiner 2000: 135) que colaboran en el intento de comprender la condición humana. Por ello este castigo ha marcado la producción literaria de generaciones, respondiendo según Sánchez a la necesidad de memoria de una herida abierta, por lo que "no será ocioso ni inactual volver de nuevo sobre el tema (...), porque sus recuerdos y reflexiones no se apagan” (2003: 574). Una herida que actualiza permanentemente las problemáticas asociadas a los eventos del desplazamiento forzado como la exclusión, el encuentro del yo con el otro, la tensión entre Estado y ciudadano y la aceptación o rechazo de la diferencia.

En dicho contexto, este artículo da cuenta del estudio de las novelas sobre el exilio chileno en la República Democrática Alemana (RDA), Morir en Berlín (1993) de Carlos Cerda, y Las dos orillas del Elba (2012) de Juan Forch. Se trata de los dos únicos textos narrativos de escritores chilenos expatriados en ese país y que al retornar a Chile ficcionalizaron esa experiencia. Son textos escritos sobre el exilio y no en el exilio, de tal manera que no integran la literatura intercultural (Carrasco 2005) sino que forman parte de la tradición literaria nacional. $\mathrm{Su}$ abordaje analítico parte del reconocimiento que este castigo fractura el discurso autocomprensivo, constructo siempre permeable a los impulsos del devenir, a través de la pérdida de uno de sus factores integrantes, el espacio físico, al que las personas están conectadas con un nivel de dependencia del que no son conscientes hasta que lo pierden (Aragonés y Amérigo 2010), razón por la cual Relph (2010) diagnostica una "falta de lugar" en nuestras vidas, determinada por la escasa reflexión sobre sus efectos. Por ello, junto con Bachelard (2000), en este estudio el espacio se entiende vivido, una materialidad que concentra ser dentro de sus límites y que por tanto supera una operacionalización "a la medida y a la reflexión del geómetra” (22). En la cotidianeidad del destierro la oposición "aquí-allá" se sobrepone al "antes-ahora" (Vásquez y Araujo 1990: 12) y se revela como eje clave de los procesos perceptivos, cognitivos y afectivos de las personas que lo sufren.

El impacto de los entornos en los procesos de construcción de identidad es de alcance individual y social en el entendido que la respuesta al quién soy implica una diferenciación respecto a los demás para lograr la confortadora unicidad, aunque también requiere identificar los puntos de encuentro con los semejantes que colaboren con la pertenencia y el sentido de igualdad. La simbiosis entre esos distintos niveles de representación identitaria tiene su correlato en los tipos de ambientes físicos que ocupamos, a partir de lo cual el análisis de las novelas incluyó los interiores, cerrados o privados -la vivienda y el lugar de 
trabajo- y los exteriores, abiertos o públicos -el barrio o suburbio, la ciudad y el país-. Dicha clasificación se adoptó sobre la base de los significados construidos sobre esos entornos que los diferencian simbólicamente, y no considerando propiedad o dominio, una distinción metodológica que tomó en cuenta las características de la República Democrática Alemana -espacio extratextual representado en los textos-, organizada de acuerdo a un sistema económico de planificación centralizada, medios de producción estatales y sin propiedad individual.

Morir en Berlín y Las dos orillas del Elba ficcionalizan el exilio chileno como experiencia del espacio, en un país que ha restringido los derechos sobre el uso del territorio nacional y que ha precarizado las condiciones de los entornos personales y compartidos. Ello provoca tal menoscabo en la propia imagen de los desterrados que la RDA, superando su efectividad como refugio y salvación, se les presenta asociada a una lenta pero efectiva muerte en el orden simbólico.

\section{EL EXILIO Y EL QUIEBRE IDENTITARIO A PARTIR DEL ESPACIO: EL EJERCICIO TEÓRICO}

Entendido como aquel castigo que consiste en expulsar a una persona del territorio al que está ligado por lazos jurídicos, históricos y afectivos, el destierro tiene una naturaleza especialmente aberrante pues transgrede el derecho a vivir en la patria o país, un principio absoluto y fundamental tan intrínseco a la condición humana que la doctrina jurídica lo considera un atributo personal como el nombre o la nacionalidad, por lo que desde un punto de vista ético es inconcebible considerar que alguien no lo posea (Esponda 1981) ${ }^{2}$.

Aplicado como mecanismo de represión por sistemas de poder que sienten amenazada su estabilidad política, religiosa, étnica o cultural, el exilio comenzó a aplicarse en Chile en 1.767, aunque nunca tuvo un alcance tan devastador como en el régimen autoritario de Augusto Pinochet, instalado a partir del quiebre institucional, político y social del 11 de septiembre de 1973 y que implicó el término del gobierno de la Unidad Popular. La expatriación por motivos políticos, en un contexto de coerción de las libertades y derechos garantizados en democracia, fue justificada para resguardar el orden social y los intereses de seguridad del Estado. El mecanismo para las deportaciones fueron decretos y decretos exentos emitidos por el Ministerio del Interior y tribunales militares, como el recordado Decreto Ley 81 que castigó el ingreso clandestino "con la pena de presidio mayor en su grado máximo a muerte". De acuerdo al Informe del Alto Comisionado de las Naciones Unidas para los Refugiados (ACNUR 2000), el total de chilenos que debió salir del país fue superior a 200.000 personas.

\footnotetext{
${ }^{2}$ Conforme a sus grados de relevancia, el también llamado derecho a residencia y tránsito está cautelado de manera integral por los principales instrumentos jurídicos mundiales, entre los cuales están la Declaración Universal de los Derechos Humanos de la ONU, la Declaración Americana de los Derechos y Deberes del Hombre y el Convenio Europeo de Derechos Humanos.
} 
Según el estudio de Koch (2017), 5.000 expatriados chilenos se refugiaron en la República Democrática Alemana entre 1973 y 1989, principalmente militantes de partidos políticos, sindicalistas y un importante grupo de intelectuales compuesto por dramaturgos, sociólogos, actores y principalmente escritores ${ }^{3}$, lo que demandó de aquel país la organización de un dispositivo que satisficiere las necesidades de la diáspora chilena. Estimulados en un principio por la cercanía ideológica entre la Unidad Popular y el gobernante Partido Socialista Unificado (SED), y por el triunfo del socialismo real, la percepción de los expatriados "iría variando con el tiempo, debido a lo restrictivo y agobiante que se iría volviendo el sistema socialista (...)" (Garay 2011: 119). Al respecto, Sol Marina Garay (2011) pone especial atención sobre el impacto del desplazamiento forzado en el proceso de representación de la propia imagen de los expatriados en Alemania Oriental:

Una concepción que resulta radicalmente fracturada durante el exilio, puesto que se trata de una experiencia que quiebra aquel esquema identitario y de pertenencia monocultural al cual estaba acostumbrado el individuo. Y que, por tanto, trastoca brutalmente la identidad del ser humano y lo lleva a cuestionar su realidad como sujeto independiente y absoluto (32).

En el pensamiento occidental la conciencia que una persona o colectividad tiene de sí misma, y que la distingue de los demás por los rasgos propios que derivan de ese ejercicio de conocimiento, ha estado ligada según Emmanuel Lévinas (1999) a la unidad del ser, una lógica radical de subjetivismo que ha hecho "una reducción de lo Otro al Mismo" (67). En las antípodas, el filósofo lituano plantea una autoconciencia en situación de apertura con la alteridad, que no se presenta como "hecha de resistencia al Mismo, sino como una alteridad anterior a toda iniciativa, a todo imperialismo del Mismo" (62). De acuerdo a Lévinas, la configuración identitaria surge entonces de una conciencia que vuelta sobre sí, pero principalmente demandada por un alter que "interviene en las mismas nociones de ser y de sujeto" (Samoná 2005: 54), se interroga y autorreflexiona extrayendo un relato con sus aspectos definitorios. A través de ese discurso coherente, que "tiene el carácter reflexivo de la inclusión de lo heterogéneo" (64), el sujeto "habla" de sí mismo a otros y se conecta con su contexto vital, germinando "la relación concreta entre un yo y un mundo" (Lévinas 1999: 61), pues el "yo no es un ser que permanece siempre el mismo, sino el ser cuyo existir consiste en identificarse, en recuperar su identidad a través de todo lo que le acontece” (60). Esta interacción con personas, sucesos e ideas constituirá el permanente suministro de una

\footnotetext{
${ }^{3}$ De acuerdo al estudio Memoria y exilio a través de la obra de escritores chilenos exiliados en Alemania (19731989): Una apertura al otro, el grupo de escritores chilenos exiliados en la República Democrática Alemana estuvo compuesto por Roberto Ampuero (también se asiló en la RFA), Víctor Carvajal, Carlos Cerda, Salvattori Coppola, Alfonso González, Sergio Macías, Guillermo Quiñones, Omar Saavedra, y Sergio Villegas. Su experiencia dialogó con la de quienes se exiliaron en la República Federal Alemana: Antonio Avaria, Nora Becker, Carlos Briones, Patricia Cerda, Cristián Cortés, Pedro Holz, Isabel Lipthay, Carlos Lira, Constanza Lira, Orlando Mardones, Antonio Skármeta, Hernán Valdés, Sergio Villarroel y Oscar Waiss.
} 
conciencia nómade, "resultado parcial de un proceso dinámico que nunca se detiene, que es puro devenir” (Fernández 2015: 430).

Uno de aquellos insumos determinantes para la articulación del autodiscurso es el espacio, entendido como los ambientes físicos, naturales o arquitectónicos en los que se desarrolla la experiencia humana, una interacción que según Tuan (2007) constituye una verdadera topofilia, lazos emocionales entre personas y lugares. Partiendo de su materialidad, e incluyendo complejos procesos fisiológicos y psicológicos, los entornos implican valores, actitudes, conductas y comportamientos (Ittelson 1978) y tienen un relevante potencial simbólico basado en que el espacio humano "ha sido siempre significante" (Barthes 1990: 257). Como resultado de esos intercambios, el espacio toma sentido cuando es significado por la persona y ésta cobra significado en tanto se ubica en un territorio significativo para ella (Valera 2010).

De acuerdo a la Psicología ambiental la participación de los lugares en la idea que de sí mismos tienen las personas se manifiesta en dos niveles de representación. Como seres pretendidamente únicos y exclusivos, diferentes a los demás, ellos participan en la imagen del self constituyendo una identidad de lugar, "recuerdos, ideas, sentimientos, actitudes, valores, preferencias, significados" (Proshansky et al. 1983: 59) que asociamos a contextos espaciales que nos identifican. Ese constructo se manifiesta en la tendencia a "marcar" los ambientes a través de ciertas señales de significado (decoración, colores, estilos, etc.) implicando una apropiación del espacio; también se expresa en el verdadero afecto que generan los entornos o apego al lugar (Vidal y Pol 2005). Cuando este complejo entramado individual es compartido se genera la identidad social urbana (Valera y Guárdia 2002), que nos identifica como miembros de un barrio, comuna, ciudad o país, satisfaciendo nuestra necesidad de sentirnos semejantes a otros.

De todos los espacios que intervienen en la configuración de lo subjetivo uno de los más decisivos es la casa, incrustada en nuestra conciencia como bienestar, refugio y anclaje emocional, razón por la cual genera una satisfacción residencial (Amérigo 1995). "El hogar es el hogar, y todo lo demás no es el hogar. Así se construye el mundo” (Klinkenborg 2012). Ella se conecta tan estrechamente con nuestra específica manera de ser que la demarcamos y defendemos, desplegando tácticas de territorialidad para informar a los demás "que ese lugar está bajo el control de una persona o grupo" (Altman en Pérez 2011: 53). El otro entorno relevante es la ciudad, que conecta con nuestra imagen social y que fue comprendida por Roland Barthes (1990) como un texto descifrable que le habla a sus habitantes, quienes despliegan estrategias de lectura como la imaginabilidad (Lynch 2015) -dibujos mentales que nos proporcionan el marco de referencia citadino-y el wayfinding, adaptación cognitiva para un desplazamiento eficaz.

\section{LAS NOVELAS SOBRE LA DIÁSPORA CHILENA EN LA RDA: EL EJERCICIO ANALÍTICO}

A partir de su carácter ficcional, Morir en Berlín y Las dos orillas del Elba "se emplazan en el tiempo unitario, largo y coherente de la dictadura y la postdictadura chilena” (Rojo 
2016: 14), constituyéndose por ello en textos de una estética representacional realista y que, siguiendo lo planteado por Cerda, hacen "una apropiación gnoseológica y axiológica adecuada de la realidad" (1988: 23).

Morir en Berlín fue publicada en Chile por Planeta en 1993 y también lo fue en la Alemania unificada y en Espańa. La novela relata el destierro de un grupo de chilenos que vive en el "ghetto", un conjunto habitacional en los suburbios de la capital de la RDA y cuyas dificultades y demandas se canalizan a través de la Oficina, una instancia seudoadministrativa que funciona en el inconfortable departamento de don Carlos, un exsenador de la Unidad Popular terminalmente enfermo y que sirve de enlace entre los refugiados y los servicios estatales. En ese espacio se abordan los problemas derivados de la extranjería, principalmente vivienda, alimentación, salud y convivencia, pero también situaciones privadas e íntimas como las de Lorena y Mario, que han llegado ahí para sellar su divorcio y desnudar sus miserias. Él se ha enamorado de Eva, la hija del Ministro del Interior de la RDA, y ella quiere rehacer su vida en México junto a sus hijos. El conflicto termina en fracaso y pérdida para todos: el senador morirá lejos de su país, Mario se quedará con una Eva inestable y celópata, y Lorena no conseguirá las visas para salir de Alemania Oriental. La obra de Cerda es, según David Gallagher (1994), "la gran novela del exilio" chileno y de acuerdo a Carlos Orellana Riera integra las quince obras literarias que permiten "entender nuestro país" (Olivárez 1997: 49).

Carlos Cerda nació en Santiago en 1942, estudió Filosofía en la Universidad de Chile, se doctoró en Literatura en la Universidad de Humboldt (Berlín Oriental) y murió en Santiago en 2001. Estuvo exiliado en la RDA durante diez años (1975 a 1985), durante los cuales escribió 3 libros y 2 artículos; al regresar a Chile publicó las novelas Por culpa de nadie (1986), Primer tiempo (1995), Una casa vacía (1996), Sombras que caminan (1999), Escrito con L (2001) y, póstumamente, El espiritu de las leyes (2005). La adscripción de Cerda a determinada clasificación generacional resulta un tanto problemática pues su producción en Alemania Oriental y en Chile lo hacen transitar entre la literatura intercultural y la tradición nacional. Algunos críticos lo encasillan, junto a Skármeta y Eltit, en lo que Goic denomina la generación de 1972 (Gotschlich 2009), aunque a su retorno convive con la generación de 1987 (Cánovas 1997), marcada a fuego por la fractura institucional de septiembre de 1973. José Leandro Urbina, por su parte, defiende su inclusión en la Nueva Narrativa de los 90 (Cortínez 2000).

Las dos orillas del Elba es un texto escrito en clave humorística que relata el exilio chileno en Dresden como una experiencia proletaria, lejos de los ámbitos de poder y de las élites intelectuales. Coque, su protagonista, ha debido abandonar sus estudios de Sociología en Chile y convertirse en obrero de la Pentacon, la fábrica de cámaras fotográficas de la RDA. Vive en uno de los edificios del "colectillo" donde combina sus monótonos días con amoríos pasajeros, hasta que al piso de arriba llega don Jesús González, un veterano dirigente de la Unidad Popular con quien inicia una genuina amistad enmarcada en la Solidarität mit Chile. Con el paso de los meses la relación se consolida hasta que la muerte de su amigo desata en Coque un proceso de desesperanza y frustración crítica al sistema, 
expuesto siempre en tono cómico. Según Patricia Espinosa (2012), el texto de Forch destaca por su verosimilitud y muestra "un personaje simbólicamente fundamental para la novela política chilena, una suerte de héroe visceral menor (...)”. Para Camilo Marks (2012), la cotidianeidad del desplazamiento forzado "es tratada con sutileza y complejidad", y prima "una picaresca de muy buena ley".

Juan Forch (1948) es periodista de la Universidad de Chile, comunicador audiovisual, productor, director televisivo, cineasta, el creador de "El show de los libros" y uno de los fundadores del canal Rock and Pop. Estuvo exiliado en la RDA donde se asentó en Dresden. Su producción literaria la componen los poemarios Viaje por la juventud (1972), Obecedario (1984), 73 epigramas upelientos (2005) y, en narrativa, los cuentos Bar Paraiso, los caminos del amor (2000) y las novelas El Campeón (2005), El abrazo del oso (2007) y Las dos orillas del Elba (2012), publicadas por Alfaguara. Por la última recibió el premio José Nuez Martín. La crítica literaria chilena no lo integra a ninguna generación.

El ejercicio analítico de Morir en Berlin y Las dos orillas del Elba, dirigido por la idea de la desestabilización identitaria a partir de la experiencia de los lugares del exilio, consideró los espacios interiores, cerrados o privados, y los exteriores, abiertos o públicos. Los primeros son aquéllos en los cuales una persona o grupo regula consciente y efectivamente la interacción con los demás y la información que ofrece de sí a través de límites concretos, definición a partir de la cual se estudian la casa o departamento y el lugar de trabajo, ambientes que colaboran en la identidad individual. Los segundos son los entornos donde la regulación de privacidad es inexistente o escasa y por tanto en ellos la interacción social es ineludible pues no hay delimitaciones manifiestas, concepto que implica el examen del territorio país, la ciudad y el barrio, los que tributan a la identidad social.

\section{Espacio pais}

El espacio nacional de los textos estudiados está constituido por la República Democrática Alemana, país que en su correlato histórico estuvo separado de su vecino occidental por una frontera de más de 1.300 kilómetros fortificados, la que constituyó una verdadera Cortina de Hierro que marcó por años el periodo conocido como Guerra Fría y que tuvo una manifestación paradigmática en el Muro de Berlín. El Primer Estado de Obreros y Campesinos en Suelo Alemán estuvo organizado sobre las bases del socialismo de Estado, con partido único, un sistema económico centralizado, factores de producción y distribución de propiedad estatal y donde el régimen de sueldos, vivienda, trabajo y seguridad social estuvo regulado.

A pesar de que la RDA es desde la perspectiva del exilio un lugar de salvación, Carlos Cerda lo ficcionaliza como lugar de la desesperanza y la falta de expectativa, donde "se había decretado la eterna continuidad de lo mismo" (150), un "buque fantasma" parecido al de "El holandés errante" en el que nadie esperaba el menor cambio, condiciones que fueron apagando el necesario vigor del proceso autorrepresentativo de los personajes. El impacto de la vivencia de ese territorio se radicaliza porque fue un destino impuesto, 
"porque así lo determinó el partido" (161), factor que les ha confirmado a los desterrados que tienen nulas posibilidades de gestión del entorno, lo que genera en ellos frustración y desasimiento, emociones que en las antípodas del apego al lugar minan el sentido de pertenencia o identificación, y afectan la seguridad y el bienestar psicológico.

La novela también revela una perturbadora coerción de los derechos sobre el espacio en la RDA, con restricciones de acceso y salida. Lorena solicita a la Oficina las visas que necesita para irse a México con sus hijos, pero don Carlos se ofusca porque en su carta ella "sugiere que aquí estamos esclavizados" (91) y porque la chilenische Patriotin se niega a entender que en el territorio de acogida no puede decidir libremente los asuntos que le competen. El conflicto entre el dirigente y la mujer crece porque ella "se atreve a formular acusaciones contra un estado amigo, lo que dada nuestra condición no corresponde".

$-¿$ ¿Y cuál es nuestra condición? -interrumpió Mario.

Tartamudeó varias veces, rojo de ira, buscando esa palabra que se resistía a su memoria. Y por fin pudo gritar los tres disparos que salieron de su boca salpicados por la explosión de sus salivas:

-iHués-pe-des!" (93).

Lo que el texto plantea es la radical distancia psicológica entre visita y dueño de casa, asociada primero a la posesión y dominio sobre el espacio y que deriva después en las posibilidades de su organización y funcionamiento. La calidad de huésped limita las tácticas de apropiación y territorialidad, mermando las necesarias cuotas de libertad, independencia y autonomía que implica el self. Esa limitación es aún más castrante si se considera que la RDA ha restringido el derecho de circulación a sus propios habitantes. Mario se queja porque no puede "entrar y salir de este país como lo hace cualquier colega extranjero de mi Facultad" (95) y don Carlos le responde que "lo que usted considera un derecho elemental es algo que aquí no tiene nadie” (95). Por eso la novela perfila una especial complicidad entre los exiliados chilenos y los germanos orientales, representados por Klauss, un ocasional compañero de baile de Lorena que le confiesa que a él también le gustaría salir del país, no para abandonarlo, sino tan solo para "saber que puedo salir" (74). Esta coerción sobre el derecho de libre tránsito es determinante para que el autorreconocimiento de los chilenos expatriados en la RDA se asocie a la opresión y al sometimiento.

Forch también revela la doble exclusión territorial que implicó el refugio en la República Democrática Alemana: primero, la del suelo patrio; segundo, la del enemigo ideológico. Coque, que ha llegado al país por decisión de "la dirigencia", asiste a un acto de bienvenida a Luis Corvalán donde cantan el "No nos moverán", y en su comicidad característica agrega: "Como estamos en la RDA, deduzco que de aquí no nos saca nadie. $\mathrm{Ni}$ a palos" (129). Por eso él advierte que los refugiados chilenos y los nacionales se parecen, pues los une el dolor, la lejanía y la soledad (188). Para el protagonista de la novela, el destierro se vive como el "exilio del exilio del exilio" (232), pues "llegamos aquí para prepararnos para el regreso y nos están instruyendo para quedarnos una eternidad. Y para 
la oscuridad" (29). Esas limitaciones despiertan en él un intenso proceso de introspección a través del cual relaciona la sustracción del espacio con las limitaciones a la libertad, factor esencial y determinante para los procesos de construcción y conducción sí mismo:

Hace años no logro tomar una decisión propia. Dejé de ser sujeto y me he convertido en un objeto, una cosa que golpean, queman, ahogan, torturan, una cosa que trasladan de un lado a otro, suben a un avión, lo bajan, suben a un bus, lo trasladan, una cosa a quien nadie consulta, una cosa con la que los otros deben convivir, una cosa que no tiene capacidad de resolver. ¡Váyanse a la mierda! Me voy a hacer católico. Ellos, por lo menos, tienen eso que llaman el libre albedrío" (19).

Recibir su pasaporte alemán tampoco reduce los cuestionamientos del protagonista de Las dos orillas del Elba, pues se da cuenta que el documento solo acredita una condición civil, pero no le provee los sentidos que soportan los ambientes y que facilitan la vinculación: "Esto es lo que soy. Un extraño, un foráneo, un forastero, un ser ajeno" (189).

\section{Espacio ciudad}

Berlín es en la novela de Cerda un espacio de extravío geográfico: "Al subir de la estación a la calle el Senador se sintió perdido (...) Necesitó un momento para distinguir las partes de un espacio conocido (...) ¿Cómo reconocer un lugar si se han perdido las señales?” (97). La capital de la RDA se presenta como un texto que no se deja leer, y que se sustrae a la comprensión de los foráneos, un vacío significante tan insalvable que el exdirigente asocia el paisaje de la capital -una multiplicación interminable de edificios con ventanas oscurascon imágenes de muerte: "un desierto de cemento, la prefiguración de un cementerio, el anticipo del final" (242). Berlín es efectivamente la capital donde morirá el senador, y en la que tampoco podrán sobrevivir simbólicamente Mario y Lorena, él porque traicionó y abandonó a sus compatriotas para estar con Eva y habitar los espacios del poder; ella porque no podrá salir de la ciudad: "Me quedo en Berlín. Moriré en Berlín" (247).

En el texto de Forch, Dresden es una ciudad con grises edificios centenarios y calles de nombres impronunciables, un territorio incapaz de mostrarse acogedor o cercano y que, en las antípodas, le devuelve a Coque un amasijo de referencias territoriales en las que no puede aplicar recursos de imaginabilidad a diferencia de quienes viven ahí: "Ellos son de aquí (...) Se mueven con absoluto control de sus actos" (21). Él en cambio se desplaza en situación de inseguridad y extravío, no solo territorial o geográfica, sino principalmente identitario: “¿Dónde queda Chile? (...) Ya no tengo claro quién soy ni de dónde vengo" (113).

La ciudad se le manifiesta a Coque con las huellas de un histórico bombardeo que permanece vivo en edificios derrumbados o protegidos por mallas de alambre, paisaje con el cual no comparte un pasado ambiental, aquel sedimento cognitivo y afectivo socialmente construido que conecta a los habitantes con el entorno citadino. Esta desvinculación del protagonista con los significados de la ciudad le dificulta el encuentro de las coordenadas 
de la propia historia y del propio concepto, pues la desorientación espacial deviene extravío existencial, y la ajenidad provisoria del exilio muta en orfandad esencial: (...) "yo soy un nowhere man" (21). Frente a ese Dresden in/significante, la experiencia de la ciudad se automatiza y se convierte en mero gesto: "El mismo tranvía, cada parada a su hora, las mismas caras, cada paisaje y cada acción (...) Esta es la cotidianeidad. Un día detrás del otro y delante del que viene. Me bajo frente a Lenin. Lo miro por centésima vez” (244). Por ello, al igual que el Berlín de don Carlos, Dresden no insufla estímulo vital: “¿(...) estamos todos muertos hace mucho tiempo?” (222).

\section{Espacio vivienda}

Uno de los niveles de espacialidad más estrechamente conectados con los procesos de autoconsciencia es el entorno privado, fuente permanente de satisfacción personal. El departamento que le asignaron a don Carlos es un cuarto "tristón" de proporciones diminutas donde cabe una sala, un baño y una cocina, y está separado del de sus vecinos por escuálidas paredes que le niegan a diario la privacidad y la reserva que necesita, pues por ellas permean los sonidos de las toses, los quejidos, la ópera, el desagüe, los ronquidos y también un insoportable olor a perro. Tan distantes del concepto de hogar, esos pocos metros (desde la cama al balcón hay solo tres zancadas) parecen "un cuarto de hotel" (21) donde el exparlamentario ha dispuesto sus pertenencias como si estuviera de paso, sin desplegar estrategias de control y marcación a través de las cuales los "dueños de casa" proyectan individualidad, valores y creencias. Pero pronto la vivienda ni siquiera será provisoria o ajena, pues devendrá en espacio de acorralamiento: "¿por qué no puede sentarse y va y viene de la cama al balcón como si recién lo hubiesen encerrado en esa jaula?” (147). Esa mínima vivienda es finalmente el "nicho" (148) que anticipa el crepuscular destino del exsenador.

En Las dos orillas del Elba, el departamento de Coque se ubica en la Hoffnungstrasse, la Calle de la Esperanza, "otra jugarreta del destino" (21) ironiza el protagonista. Allí la vida oscila entre "un gris inmisericorde" (21) y la oscuridad de un "pozo" (78), bastante lejos de la vitalidad que implica la vivienda como lugar de extensión del self, asociada a sensaciones de confort y principalmente de arraigo. Los pocos metros cuadrados de la vivienda de Coque son para él todo lo contrario, pues fijan el punto de referencia de su ajenidad:

Miro la ventana y el cielo. Ese cielo no me pertenece. Ni yo le pertenezco. No hemos nacido el uno para el otro. No nos reconocemos. Ni el cielo ni la ventana son míos. Ni lo que existe bajo ese cielo ni lo que hay tras esa ventana (148).

Esa experiencia del entorno lleva tal carga de melancolía que afecta incluso la percepción del tiempo, que "está pasando demasiado lento, se arrastra. Y de pronto me doy cuenta de que llevo años en este lugar" (189). Por eso Coque cree que se ha mimetizado entre esas cuatro paredes, aunque su cuestionamiento es aún más profundo y se relaciona 
con la pertenencia, aquel factor que posibilita la solidez de la imagen autorrepresentativa: "Estoy aquí, pero no soy de aquî" (189).

\section{Espacio barrio}

Si de acuerdo a Psicología ambiental los entornos suburbiales allanan los vínculos que generan pertenencia e identidad social, en las novelas están descritos a través de evidentes códigos de segregación que impiden el logro de ese objetivo. Don Carlos vive en "la crepuscular" (18) Volksradstrasse, un vecindario de bloques de 170 departamentos iguales cuyos pasillos huelen a excremento de mascotas y donde sus habitantes miran pasar las aguas contaminadas desde sus mínimas terrazas, un modo de disposición vecinal que "puede acercar bastante el infierno a la tierra" (13). Harto más lejos del centro histórico y político de Berlín, en la Elli Voigt Strasse, vive la mayoría de los chilenos refugiados, un conjunto de edificios cuya gris regularidad se acrecienta con sus miles de pequeñas ventanas y diminutos balcones y que ellos llaman el ghetto. Los doce años que Lorena lleva ahí han sido como "ir muriendo de a poco" (60), estando "aquî", pero sabiendo que la vida está "allâ", un proceso de autoconciencia que la rotula como ciudadana de segunda. Allí la individualidad está permanentemente frustrada por un uso compartido del espacio, la promiscuidad y la inclinación a compartir todo: vacaciones, ropa, comida, secretos. Pero también entre las antipatías, aversiones y exclusiones, generando un ambiente donde la historia común, las creencias y los estilos de vida ya no son suficientes para generar un perfil identitario y concluyen más bien en un exilio interior.

En Dresden, Coque vive en "el desierto de los tártaros" (42), un barrio de obreros y técnicos del socialismo real donde los chilenos asilados comparten en el "colectillo", un lugar que en términos de convivencia se parece a una "Troya multifamiliar" (56) donde la autoapropiación y la gestión de lo privado están seriamente obstaculizadas, igual que la interacción con el "exterior". Ese conjunto de oscuros edificios iguales de diez pisos y ciento cincuenta ventanas uniformadas, armados según el método soviético con bloques de muros con cañerías a la vista y balcones embutidos y alternados, es para los chilenos asilados en Dresden una señal evidente de la exclusión socioespacial. Desde allí Coque ve con envidia esas otras construcciones de solo cinco pisos y cuarenta metros de largo, de "tamaño humano y carácter acogedor" (145) en las que viven los nacionales. Al igual que Cerda, Juan Forch asocia ese entorno suburbial con imágenes de muerte, abandono y decepción: "Todo este edificio es una suma de nichos en los que cada uno de nosotros se guarda cada noche para amanecer al otro día creyendo que hay un mañana" (222).

\section{Espacio de trabajo}

En Morir en Berlín el lugar de trabajo no está constituido por fábricas, universidades o el comercio, sino por la Oficina, la sección de Control y Cuadros que resuelve las dificultades de los chilenische Patriotin en permanente consulta con las instancias gubernamentales, 
lo que provoca en los allegados la perturbadora certeza de estar sometidos a dos normas, dos leyes y dos autoridades. Desde su céntrica y señorial ubicación en la Heinrich Mann Strasse, la Oficina se ha trasladado nada menos que al departamento de don Carlos, en los suburbios de Berlín. Allí, en ese "cuarto de hotel" mínimo y hediondo, el dirigente recibe a los allegados chilenos que acuden a exponer sus necesidades y problemas, discutidos en ese entorno doméstico e incómodo, sin garantías de discreción e impropio para la naturaleza de los asuntos que allí se tratan, lo que redunda en un permanente menoscabo para la dignidad de los desterrados. La Oficina es precisamente el espacio donde se traspasa el límite que distingue los ambientes públicos o abiertos de los íntimos o cerrados, y por tanto donde las personas no disponen de los mecanismos para organizar eficazmente la entrega de información propia, con la consecuente perturbación psicológica y emocional. Lorena es la única que se da cuenta que esa restricción deteriora su estima:

De pronto comprendió que al aceptar la existencia de la Oficina se aceptaba por consecuencia directa toda su secuela, esa condición de persona de segunda clase que debe someterse a dos normas, a dos leyes y a dos autoridades. Se aceptaba también el ghetto y se abría la puerta para que con el tiempo se constituyera un doble estatus, una nueva relación de poder dentro de otro sistema de poder y finalmente un exilio dentro de otro exilio (63).

En el exilio obrero perfilado por Forch, Coque trabaja como empleado en la sección de Control de Calidad de la Pentacon, la fábrica nacional de cámaras fotográficas. Allí todo está pintado "color burro" (24) -puertas, galpones, muros, estanterías y muebles-, entorno donde él ejecuta sin pausa y variación su secuencia productiva: caja-pieza-matriz-brochaaceite-broca-palanca-pieza-caja. Y desde su puesto, Coque se pregunta cómo será trabajar en algo que aporte, cómo escapar de "la monotonía de esta vida (...)" (117), pues "yo no quiero subsistir. Yo necesito existir" (101). Es que en Chile quedaron sus frustradas intenciones profesionales e intelectuales, el deseo de ser sociólogo y escribir un libro, pero él está en Dresden, "enterrado en la Pentacon pelándome el lomo como obrero" (203), mecanizado en el exilio proletario de su fábrica color burro, asociada a la desesperanza, la frustración, la falta de expectativa y a la lápida del lugar donde está "enterrado".

\section{El EJERCICIO CONCLUSIVO}

Morir en Berlin y Las dos orillas del Elba, novelas escritas por autores efectivamente desterrados en la República Democrática Alemana, visibilizan el impacto de un castigo cruel y antinómico con los derechos humanos que implica el fin de un confortable modus vivendi y la pérdida de los sistemas de referencia individual y comunitario. Entre estos últimos, el espacio tiene una especial potencia pues no solo se entiende como recipiente de las acciones, sino principalmente como motor emocional, afectivo y conductual de las personas. Es que 
superando su materialidad, el territorio implica significados y vínculos que tienen el mismo nivel de relevancia que el contacto con los pares y que se expresan en la identidad de lugar, uno de los sustratos de nuestro relato definitorio que como constructo sujeto al dinamismo levinasiano es gravemente impactado por el destierro.

El análisis de las novelas da cuenta que la salida forzada y traumática del confortable suelo nacional desmantela la consistencia del yo garantizada por el bienestar monoespacial. Por el contrario, en el destierro los personajes son incompetentes para identificar los referentes físicos, históricos y culturales de los lugares con los que se relacionan, requisito central para su organización y gestión coherente, lo que deriva en una experiencia descentrada del entorno surgida a partir del extravío y la vulnerabilidad. Ese proceso de des/localización determinada por la ajenidad, etiqueta a los chilenos desterrados como un permanente otro, renunciando a la poderosa inclinación del yo hacia la autosuficiencia y la completud, y adoptando con ello el factor menospreciado de un binomio que, en la contraparte, tiene instalado a un mismo potenciado y ocupando los espacios de poder. Se trata de la diferencia entre anfitrión, concebido literalmente como "dueño" de casa y portador de los códigos que dirigen la ocupación del espacio, y refugiado o forastero, restringido en sus márgenes de acción y transformación sobre el entorno. Ello se tensiona aún más en el caso de los chilenos desterrados en la RDA, donde grupos políticos canalizan los requerimientos de la vida cotidiana, pero en otras ocasiones sancionan aspectos personales e íntimos, restricción extrema de la autodeterminación.

Los textos revelan también que el destierro obstaculiza la incorporación de los ambientes físicos privados y públicos como agentes autoconstitutivos pues no soportan los sentidos y significados que los convierten en "nuestros", condición de propiedad que coopera a su vez en el sentido de la existencia. Esa in/significancia espacial se conduce a través de un desapego afectivo, valórico, actitudinal y conductual respecto al entorno y que deriva en episodios de melancolía intensa, sensación de abandono, desesperanza y abatimiento, perfilando a los desterrados como personas gravemente necesitadas desde un punto de vista psicológico y psicosocial.

La intervención del ambiente físico en el proceso de construcción identitaria de los desplazados se presenta en las novelas asociada a las características de los dos tipos de entornos representados. Por un lado, los espacios cerrados (casa y lugar de trabajo), aquellos que se vinculan con lo más propio e individual, son descritos en términos depreciados a partir de sus dimensiones, ubicación, habitabilidad, materiales y tipo de construcción, pero principalmente respecto a su ineficacia para la administración de la privacidad. Esos ambientes "menos "humanos" que los ocupados por los germanos orientales exacerbaron el necesario proceso de diferenciación identitaria con los demás, generando una autoimagen conectada con la alteridad radical que derivó en episodios de individuación extrema, repliegue del entorno que dificultó gravemente la trama autocomprensiva.

Por otro lado, los espacios abiertos (ciudad y barrio), a través de los cuales se vehiculan las configuraciones intersubjetivas que construyen identidad social, también fueron ineficaces para los protagonistas en su intento de construir un discurso articulado 
sobre sí mismos. El ambiente citadino fue incapaz de tornarse "legible", y por tanto se vivenció como mero continente de un automático y repetitivo desplazamiento, provocando una autoevaluación decreciente gatillada por la imposibilidad de incorporarlo como suministro psicosocial con contenido significativo. Eso generó en los grupos de exiliados una respuesta dada por la regresión social, que en todo caso intentaron aminorar con la pertenencia a grupos constituidos por "los mismos" en los espacios del guetto y el "colectillo", efectivo sucedáneo para los necesarios puntos de encuentro que requiere el self. Sin embargo, esos territorios "cercados" simbólicamente por la segregación y discriminación, generaron una identidad socioespacial vicaria y por tanto ineficaz. Con el paso de los años, la experiencia de vida en el barrio de los exiliados culminó en un proceso de desindividuación o pérdida de la autoconciencia propiciada por el anonimato que siempre facilita la pertenencia a un grupo.

De acuerdo a ambas novelas, en todo caso, el espacio nacional fue decisivo para la comprensión del impacto del desplazamiento forzado en el ejercicio de construcción identitaria. En ellas se refieren las dificultades que provocó en los personajes la interacción obligada con un territorio asociado a costumbres, pasado histórico, condiciones físicas, ubicación geográfica e idioma ajenos, lo que produjo en ellos un desgaste psicológico y emocional de tal alcance y profundidad que asociaron ese país a los nombres connotativos de exclusión ("prisión"), escasez de vida ("desierto"), castigo ("infierno" y "esclavitud”) y final ("cementerio"). Sin embargo, fue la restricción sobre el derecho elemental del libre tránsito en la RDA, y la imposibilidad de salir de allí, lo que produjo la desestabilización del "yo" de los exiliados, que experimentaron lo que Bachelard propone como una dialéctica del adentro y el afuera, donde los contrapuntos interior/exterior y aquí/allá dejaron de constituir meras referencias espaciales y adquirieron una relevancia ontológica que implicó la distancia entre la existencia y la pura subsistencia, entre la energía propulsora y edificante del ser $y$ la inercia del estar.

En esas condiciones el yo de los personajes fue sitiado entre la obligatoriedad del abandono y la obligatoriedad de la permanencia, un "exilio dentro del exilio" que redujo, y otras veces agotó, las posibilidades de autodeterminación, toma de decisiones y control de la vida. En el encierro y sin salida, y ocupando espacios que carecieron de vida, las respuestas al quién soy fueron frustrándose y reduciéndose de tal manera que quedaron como un relato vacuo e inconsistente asociado más bien al menoscabo y la indignidad... más bien una "condena a muerte" en los in/significantes espacios del destierro.

\section{Obras CITADas}

ACNUR. 2000. La situación de los refugiados en el mundo. Cincuenta años de Acción Humanitaria. Barcelona: Icaria.

Amérigo, María. 1995. Satisfacción residencial. Un análisis psicológico de la vivienda y su entorno. Madrid: Alianza Universidad. 
Aragonés, Juan Ignacio y María Amérigo, coords. 2010. Psicología ambiental. Madrid: Pirámide.

Bachelard, Gastón. 2000. La poética del espacio. Buenos Aires: Fondo de Cultura Económica. Barthes, Roland. 1990. La aventura semiológica. Barcelona: Paidós Comunicación.

Cánovas, Rodrigo. 1997. Novela chilena, nuevas generaciones, el abordaje de los huérfanos. Santiago: Ediciones Universidad Católica de Chile.

Carrasco, Iván. 2005. "Literatura intercultural chilena: proyectos actuales". Revista Chilena de Literatura 66: 63-84.

Cerda, Carlos. 1988. José Donoso. Originales y metáforas. Santiago: Planeta. 1993. Morir en Berlín. Santiago: Planeta.

Cortínez, Verónica, ed. 2000. Albricia: la novela chilena de fin de siglo. Santiago: Cuarto Propio.

Espinosa, Patricia. 2012. "Un héroe visceral". Las Últimas Noticias, 13/07: 58

Esponda, Jaime. 1981. "El exilio, aspectos jurídicos”. Mensaje 305: 698-705.

Fernández, Olaya. 2015. "Levinas y la alteridad: cinco planos". Brocar 39: 423-443.

Forch, Juan. 2012. Las dos orillas del Elba. Santiago: Alfaguara

Gallagher, David. 1994. "Con culpa en Berlín”. El Mercurio, 19/08: A3

Garay, Sol. 2011. Memoria y Exilio a través de la obra de escritores chilenos exiliados en Alemania (1973-1989): Una apertura al otro. Tesis Doctoral. Web. 19 de septiembre de $2020<$ http://repositorio.conicyt.cl/handle/10533/179706>

Gotschlich, Guillermo. 2009. "Entrevista a Cedomil Goic". Revista Chilena de Literatura 75: $317-323$.

Ittelson, William. 1978. "Environmental perception and urban experience". Environment and Behavior 10.2: 193-213.

Klinkenborg, Verlyn. 2012. "The definition of home". Web. 17 de septiembre de 2020 $<$ https://smithsonianmag.com/science-nature/the-definition-of-home-60692392>

Koch, Sebastian. 2017. Zufluchtsort DDR?: Chilenische Flüchtlinge und die Ausländerpolitik der SED. Paderborn: Ferdinand Schöningh.

Lévinas, Emmanuel. 1999. Totalidad e infinito. Ensayo sobre la exterioridad. Salamanca: Sígueme.

Lynch, Kevin. 2015. La imagen de la ciudad. Barcelona: Gustavo Gili.

Marks, Camilo. 2012. "Solidarität mit Chile". El Mercurio, 15/07: E19.

Olivárez, Carlos, ed. 1997. Nueva narrativa chilena. Santiago: Lom Ediciones.

Pérez, Raquel. 2011. La vivienda como símbolo de identidad personal y social. Tesis doctoral. Web. 19 de septiembre de 2020 <https://ruidera.uclm.es/xmlui/ bitstream/ handle/10578/2320/TESIS\%20Pérez\%20López.pdf?sequence=1>

Proshansky, Harold, Abbe Fabian y Robert Kaminoff. 1983. "Place-identity: Physical world socialization of the self". Journal of Environmental Psychology 3.1: 57-83.

Relph, Edward. 2010. Place and Placelessness. Londres: Pion Limited.

Rojo, Grínor. 2016. Las novelas de la dictadura y la postdictadura chilena: ¿Qué y cómo leer? Santiago: Lom Ediciones. 
Samoná, Leonardo. 2005. Diferencia y alteridad. Madrid: Akal.

Sánchez, Adolfo. 2003. "Entre la memoria y el olvido". A tiempo y destiempo. México D. F.: Fondo de Cultura Económica.

Steiner, George. 2000. Antígonas. La travesía de un mito universal por la historia de Occidente. Barcelona: Gedisa.

Tuan, Yi-Fu. 2007. Topofilia: Un estudio sobrepercepciones, actitudesy valores medioambientales. Santa Cruz de Tenerife: Melusina.

Valera, Sergi. 2010. "Identidad y significado del espacio urbano desde una perspectiva socioambiental. Nuevo espacio público y nuesvos retos sociales". Arquitectonics 1920: $125-136$.

Valera, Sergi y Joan Guárdia. 2002. "Urban identity and sustainability". Environment and Behavior 34.1: 54-66.

Vásquez, Ana y Ana María Araujo. 1990. La maldición de Ulises. Repercusiones psicológicas del exilio. Santiago: Editorial Sudamericana.

Vidal, Tomeu y Enric Pol. 2005. "La apropiación del espacio: una propuesta teórica para comprender la vinculación entre las personas y los lugares". Anuario de Psicología 36.3: 281-297. 